\title{
Analyses of extraterrestrial samples using quadrupole ICP-MS
}

\author{
F. WOMBACHER ${ }^{1}$, N. BRAUKMÜLLER ${ }^{1}$, L. KAUFMANN ${ }^{1}$, \\ W. ABOUCHAMI ${ }^{1}$, C. MÜNKER ${ }^{1}$ AND A. BISCHOFF ${ }^{2}$ \\ ${ }^{1}$ Institut für Mineralogie and Geologie, Universität zu Köln, \\ Germany, fwombach@uni-koeln.de. \\ ${ }^{2}$ Institut für Planetologie, Universität Münster, Germany.
}

The elemental composition of planetary materials provides fundamental insight into the processes that lead to their formation. Here, major and trace element abundances in carbonaceous chondrites and lunar samples were determined using an iCap quadrupole ICP-MS. Quantification was based on matrix matched calibration and $\mathrm{Rh}$ and $\mathrm{Re}$ internal standards. For some samples, eight volatile elements $(\mathrm{Cu}, \mathrm{Zn}$, $\mathrm{Ga}, \mathrm{Ag}, \mathrm{Cd}, \mathrm{In}, \mathrm{Sn}$ and $\mathrm{Tl}$ ) were also determined by isotope dilution following chemical separation.

For chondrites, 56 elements were determined via external calibration. Nine replicates for the Allende Smithsonian reference powder yielded relative 2 standard deviations typically much better than $5 \%$ ( $9 \%$ for Se; $14 \%$ for $\mathrm{Be}$ ). Results agree with Allende reference data within $10 \%$ for 47 elements, while data for $\mathrm{Sn}, \mathrm{Lu}, \mathrm{Th}, \mathrm{Cs}, \mathrm{W}, \mathrm{Pb}, \mathrm{Ag}, \mathrm{Be}$ and Ga differ by 12 to $41 \%$. Most data for a second digestion of the Allende Smithsonian powder agree within a few percent, except for six elements which deviate by up to $15 \%$. The elemental composition of the ungrouped desert find Acfer 094 (C2) is very similar to that of CM2 chondrites, while those of Sahara 0182 (C3), DaG 056 (C3) and $\mathrm{HaH} 073$ (C4) are about similar to those observed for $\mathrm{CO} 3$ and $\mathrm{CV} 3$ chondrites, but with a stronger depletion of $\mathrm{Tl}$, In and $\mathrm{Cd}$. The previous observation, that plateau volatile elements with condensation temperatures between 800 and $500 \mathrm{~K}$ are uniformly depleted in many carbonaceous chondrites, is corroborated by new data for $\mathrm{C} 2, \mathrm{CM}, \mathrm{CR}, \mathrm{CO}$ and $\mathrm{CV}$ chondrites as well as by isotope dilution analyses of volatile elements for Orgueil, Murchison and Allende.

Isotope dilution applied to six Apollo samples revealed comparatively high volatile element abundances in three soil samples, including orange glass soil 74220. Ferroan anorthosite 60025 displays high abundances for the most volatile elements In and $\mathrm{Tl}$ while impact melt breccia 65015 and basalt 70017 display the strongest depletions. External calibration ICP-MS yields reasonable agreement with isotope dilution data for $\mathrm{Cu}, \mathrm{Cd}$, In and $\mathrm{Tl}$ and with much of the available literature data. 